\title{
White-light phosphorescence emission from a single molecule: application to OLED $\dagger$
}

\author{
Henk J. Bolink, ${ }^{a}$ Filippo De Angelis, ${ }^{b}$ Etienne Baranoff, ${ }^{c}$ Cédric Klein, ${ }^{c}$ Simona Fantacci, ${ }^{b}$ \\ Eugenio Coronado, ${ }^{a}$ Michele Sessolo,${ }^{a}$ K. Kalyanasundaram, ${ }^{c}$ Michael Grätzel ${ }^{c}$ \\ and Md. K. Nazeeruddin $* c$
}

Received (in Cambridge, UK) 5th May 2009, Accepted 1st June 2009

First published as an Advance Article on the web 23rd June 2009

DOI: $10.1039 / b 908946 b$

A simple mononuclear cyclometallated iridium(III) complex exhibits white photo- and electro- luminescence in the wavelength range from 440 to $800 \mathrm{~nm}$, which originates from a single emitting excited state of mixed character.

Organic light emitting diodes (OLEDs) are recently proposed as one of the most appealing solutions for low energy consumption solid-state lighting. ${ }^{1}$ To date organic white light-emitting devices (WOLEDs) are obtained by combining the emission from red, green and blue or sky-blue and orange emitters. The combination of these emitters can be achieved by the deposition of multiple layers on top of each other, ${ }^{2}$ by mixing them into one single emitting layer, ${ }^{3}$ combinations of the two techniques, ${ }^{4}$ and by combining them into polymeric structures. ${ }^{5}$ These approaches require more complex device architectures and production processes compared to singleemitter based OLEDs, which has so far greatly hindered their market entry. Therefore, the development of a white lightemitting phosphorescent single transition-metal complex is very much desired. Multinuclear complexes ${ }^{6}$ or excimers ${ }^{7}$ have been designed for such a purpose. However, despite being single molecules, those approaches still rely on the combination of two emitting centers, which is expected to show color drift over time. In this paper, we describe a simple mononuclear organometallic complex that exhibits white photo- and electro-phosphorescence as a proof of concept demonstrating that WOLEDs with a single emitting center can be achieved. Theoretical calculations rationalize the reasons behind such broad emission, opening the way for generalization of this new strategy for WOLEDs development. Our result demonstrates that low-cost white light-emitting OLEDs with a single emitting center can be achieved.

An usual synthetic route was used to prepare the complex (acetylacetonato)bis(1-methyl-2-phenylimidazole)iridium(III),

\footnotetext{
${ }^{a}$ Instituto de Cienca Molecular, Universidad de Valencia,

P.O. Box 22085, Valencia, ES-46071, Spain.

E-mail: henk.bolink@uv.es; Fax: +34 963543273;

Tel: +34963544416

${ }^{b}$ Istituto CNR di Scienze e Tecnologie Molecolari,

Università di Perugia, Italy. E-mail: filippo@thch.unipg.it;

Fax: + 39 0755855606; Tel: + 390755855522

${ }^{c}$ Institute of Chemical Sciences and Engineering, Swiss Federal Institute of Technology, Lausanne, CH-1015, Switzerland.

E-mail: mdkhaja.nazeeruddin@epfl.ch;Fax: +41 216936124;

Tel: +41216934111

$\dagger$ Electronic supplementary information (ESI) available: Experimental details; supplemental figures; computational results. CCDC 730761 For ESI and crystallographic data in CIF or other electronic format see DOI: $10.1039 / \mathrm{b} 908946 \mathrm{~b}$
}

hereafter labelled as N966 (Fig. 1 and S1 (ESI $\dagger$ ) for the crystal structure). The UV-Vis absorption spectrum of $\mathrm{N} 966$ in $\mathrm{CH}_{2} \mathrm{Cl}_{2}$ solution at $298 \mathrm{~K}$ displays bands in the $\mathrm{UV}$ at 260 , 284, 308, 348 and $376 \mathrm{~nm}$, and the visible region at 408 and $454_{\mathrm{sh}} \mathrm{nm}$ due to intra-ligand $\left(\pi-\pi^{*}\right)$ and metal-to-ligand charge transfer transitions (MLCT), respectively (Fig. 1). When excited at $298 \mathrm{~K}$ within the ligand $\left(\pi-\pi^{*}\right)$ and MLCT absorption bands, the N966 complex shows a broad and almost unstructured emission covering the spectral range from 440 to $800 \mathrm{~nm}$, with a maximum intensity at $570 \mathrm{~nm},{ }^{8}$ a photoluminescence quantum yield (PLQY) of 0.015 and a radiative lifetime of $(1.96 \pm 0.1) \mu$ s over the entire spectrum (Fig. S3 and S4, ESI $\dagger$ ). The emission spectrum is independent of the excitation wavelength. Additionally, the excitation spectrum is independent of the probed wavelength (Fig. S5, ESI $\dagger$ ). Finally, emission spectra measured at concentrations ranging from $10^{-3}$ to $10^{-7} \mathrm{M}$ exhibit the same broad shape excluding the presence of an excimer (Fig. S6, ESI $\dagger$ ). At $77 \mathrm{~K}$, the emission becomes more structured with clear peaks at 469 , 504 and $544 \mathrm{~nm}$, as well as unresolved shoulders at 588 and $632 \mathrm{~nm}$ (Fig. S7, ESI $\dagger$ ). Those photophysical results point toward a single broad emitting center. Cyclic voltammetry in DMSO solution exhibits reversible oxidation and reduction peaks at 0.17 and $-3.3 \mathrm{~V} v s$. ferrocene, respectively.

To provide insight into the electronic structure and the optical properties of the N966 complex we performed DFT/TDDFT calculations on its ground singlet and on the two lowest triplet excited states, the latter corresponding to the lowest SCF triplet states obtained by population of the LUMO and LUMO $+2\left(\mathrm{~T}_{1}\right.$ and $\mathrm{T}_{2}$, respectively). For

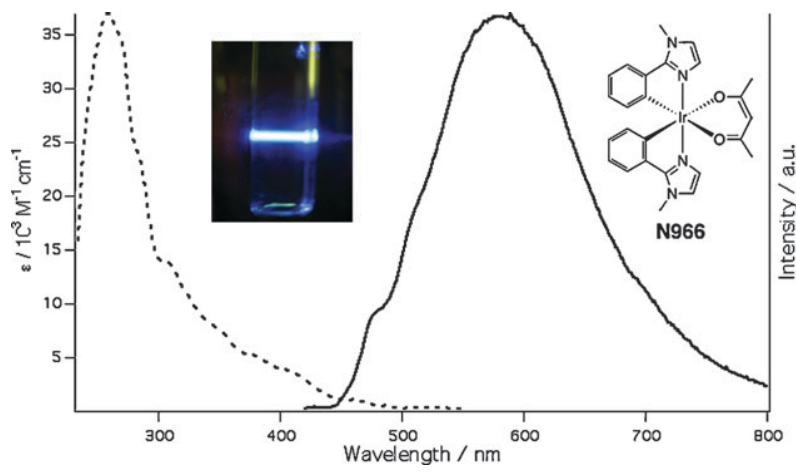

Fig. 1 Absorption (left dotted line) and emission spectra (right full line) of N966 in dichloromethane. The inset shows the chemical structure of N966. The photo shows the white-light emission of N966 obtained upon excitation using $355 \mathrm{~nm}$ laser light. 
comparison, we also investigated the well-known (acetylacetonato)bis(2-phenylpyridine)iridium(III), hereafter [ $\operatorname{Ir}(\mathrm{ppy})_{2} \mathrm{acac}$, which shows green luminescence at $516 \mathrm{~nm}$ in $\mathrm{CH}_{2} \mathrm{Cl}_{2}$ with a much less broad emission spectrum, spanning the 470-650 nm range. ${ }^{9}$ The main structural parameters of the ground $\left(\mathrm{S}_{0}\right)$ and lowest excited states $\left(\mathrm{T}_{1}\right.$ and $\left.\mathrm{T}_{2}\right)$ for $\mathrm{N} 966$ and $\left[\operatorname{Ir}(\mathrm{ppy})_{2}\right.$ acac] are rather similar, see Table S1 (ESI $\dagger$ ) for a comparison with crystallographic data. The two complexes share the same HOMO of $\operatorname{Ir}\left(\mathrm{t}_{2 \mathrm{~g}} ; \mathrm{d}_{x y}\right)$ - ppy $(\pi)$ character lying at -4.84 and $-5.13 \mathrm{eV}$ in N966 and [ $\operatorname{Ir}(\mathrm{ppy})_{2}$ acac], respectively (not shown). This decrease in the oxidation potential in N966 is in agreement with the trend of electrochemical data, which locates the [Ir(ppy) ${ }_{2}$ acac] (N966) oxidation potential at $0.37(0.17) \mathrm{V} v s$. ferrocene. The HOMO destabilization in N966 is due to the increased donor capability of the N966 cyclometallated ligands compared to the phenylpyridine ligands of $\left[\operatorname{Ir}(\mathrm{ppy})_{2} \mathrm{acac}\right]$. For $\left[\operatorname{Ir}(\text { ppy })_{2}\right.$ acac] the LUMO/LUMO + 1, see Fig. 2, are degenerate $\pi^{*}$ orbitals of the ppy ligands, lying at $-1.53 /-1.51 \mathrm{eV}$, followed at higher energy ( $c a .0 .5 \mathrm{eV}$ above) by a second degenerate couple of antibonding orbitals localized on the ppy and acac ligands at $-1.04 /-1.00 \mathrm{eV}$ (LUMO+2 and $\mathrm{LUMO}+3$, respectively). Notice that, given the energetic proximity of $\mathrm{LUMO}+2 / \mathrm{LUMO}+3$, at the[ $\operatorname{Ir}(\text { ppy })_{2}$ acac] $\mathrm{T}_{1}$ optimized geometry, the order ot these two orbitals is inverted. For N966, the LUMO is a $\pi^{*}$ orbital delocalized over the cyclometallated ligands. However, in relation to the destabilization of this orbital due to the increased donor capability of the bis(1-methyl-2-phenylimidazole) ligands, a considerable mixing of the cyclometallated and acac-based $\pi^{*}$ orbitals in the LUMO +1 and $\mathrm{LUMO}+2$ occurs. This provides a set of three almost degenerate LUMOs, Fig. 2.

The results of TDDFT excited-state calculations are summarized in Table 1. The calculated absorption spectrum for N966 (Fig. S9, ESI $\dagger$ ) is in good agreement with the experimental one, being slightly shifted towards higher energies by only $c a$. $0.15 \mathrm{eV}$. As found for related Ir(III) cyclometallated complexes, ${ }^{10}$ the visible region is dominated by MLCT transitions, while at higher energy the $\pi-\pi^{*}$ excitations of the cyclometallated ligands are found. At the ground state geometries $\left(S_{0}\right.$ in Table 1$)$, the lowest excited state of

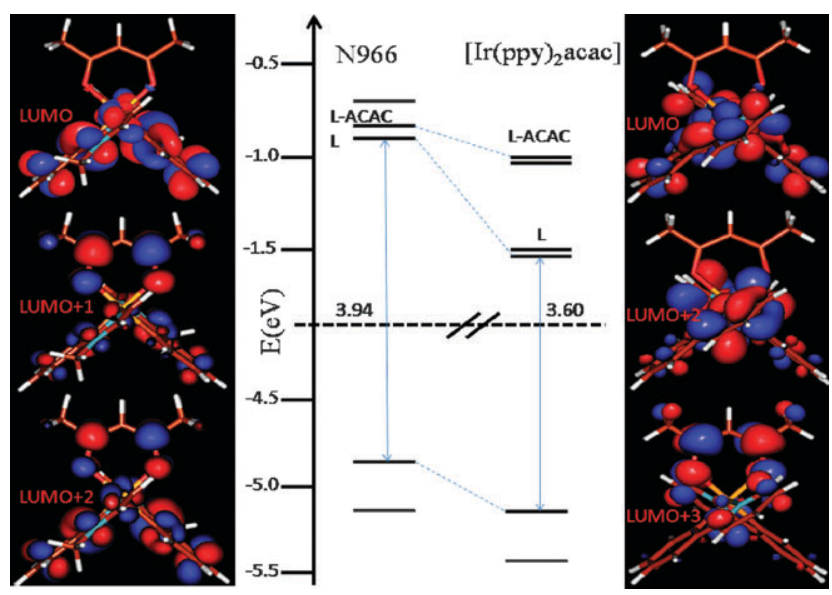

Fig. 2 Schematic representation of the frontier molecular orbitals for the N966 and $\left[\operatorname{Ir}(\mathrm{ppy})_{2}\right.$ acac] complexes calculated at the $\mathrm{S}_{0}$ geometries. Plots of relevant unoccupied orbitals are also reported.
Table 1 Selected lowest calculated $\mathrm{S}_{0}-\mathrm{T}_{n}$ and $\mathrm{S}_{0}-\mathrm{S}_{n}$ transitions (nm) for $\left[\operatorname{Ir}(\mathrm{ppy})_{2} \mathrm{acac}\right]$ and $\mathrm{N} 966$ along with their numbering and composition in terms of main orbital contributions. For $\mathrm{S}_{0}-\mathrm{S}_{n}$ transitions the oscillator strength is also reported (data in parentheses)

\begin{tabular}{|c|c|c|c|c|c|c|c|}
\hline \multirow[t]{2}{*}{ Transition } & \multicolumn{3}{|c|}{$\left[\operatorname{Ir}(\text { ppy })_{2} \mathrm{acac}\right]$} & \multicolumn{4}{|c|}{ N966 } \\
\hline & $n$ & $\mathrm{~S}_{0}$ & $\mathrm{~T}_{1}$ & $n$ & $\mathrm{~S}_{0}$ & $\mathrm{~T}_{1}$ & $\mathrm{~T}_{2}$ \\
\hline $\mathrm{S}_{0}-\mathrm{T}_{n} \mathrm{H} \rightarrow \mathrm{L}$ & 1 & 482 & 537 & 1 & 440 & 494 & 480 \\
\hline $\mathrm{S}_{0}-\mathrm{T}_{n} \quad \mathrm{H} \rightarrow \mathrm{L}+1$ & 2 & 479 & 515 & 2 & 433 & 472 & 469 \\
\hline $\mathrm{S}_{0}-\mathrm{T}_{n} \mathrm{H} \rightarrow \mathrm{L}+2$ & $3 / 5$ & - & 429 & 3 & 431 & 431 & 439 \\
\hline $\mathrm{H} \rightarrow \mathrm{L}+3$ & - & 432 & - & - & - & - & - \\
\hline $\mathrm{S}_{0}-\mathrm{S}_{n} \quad \mathrm{H} \rightarrow \mathrm{L}$ & 1 & $440(0.047)$ & - & 1 & $390(0.078)$ & - & - \\
\hline $\mathrm{S}_{0}-\mathrm{S}_{n} \mathrm{H} \rightarrow \mathrm{L}+1$ & 2 & $434(0.001)$ & - & 2 & $383(0.007)$ & - & - \\
\hline $\mathrm{S}_{0}-\mathrm{S}_{n} \mathrm{H} \rightarrow \mathrm{L}+2$ & $6 / 5$ & $366(0.023)$ & - & 3 & $369(0.000)$ & - & - \\
\hline
\end{tabular}

N966 is calculated to be of triplet character at $440 \mathrm{~nm}$; the lowest singlet excited state is calculated as a quite intense transition $(f=0.078)$ at $390 \mathrm{~nm}$. Both $\mathrm{S}_{0}-\mathrm{T}_{1}$ and $\mathrm{S}_{0}-\mathrm{S}_{1}$ originate from excitation from the metal-based HOMO to the $\pi^{*}$ LUMO of the cyclometallated ligands; the calculated transition wavelengths nicely compare with the $454 \mathrm{~nm}$ shoulder and more intense $408 \mathrm{~nm}$ band found in the absorption spectrum, suggesting that the $454 \mathrm{~nm}$ shoulder originates from spin-forbidden singlet-triplet excitations, which become allowed due to the strong spin-orbit coupling of the $\operatorname{Ir}(\mathrm{III})$ metal centre. In $\left[\operatorname{Ir}(\mathrm{ppy})_{2}\right.$ acac] the $\mathrm{S}_{0}-\mathrm{T}_{1}$ and $\mathrm{S}_{0}-\mathrm{T}_{2}$ transitions are almost degenerate (482 and $479 \mathrm{~nm}$ ), reflecting the degeneracy of the phenylpyridine based LUMO/LUMO +1 . The lowest triplet transition involving a sizable amount (ca. 35\%) of acac-based LUMO + 3 is calculated at higher energy, $432 \mathrm{~nm}$, reflecting the molecular orbital energies discussed above. In N966 the lowest $\mathrm{S}_{0}-\mathrm{T}_{n}$ transitions, related to population of the cyclometallated-based LUMO, LUMO +1 and acac-based $\mathrm{LUMO}+2$, are, on the other hand, found at essentially the same energy (440, 433 and $431 \mathrm{~nm}$, respectively); recalling the degeneracy and character of the three N966 LUMOs, our data indicate comparable contributions to the lowest excited states by the cyclometallated and acac ligands. This degeneracy is only partly resolved at the excited state relaxed geometries, for which we still calculate the two lowest excited states to lie within $c a$. $0.1 \mathrm{eV}$. This is opposed to the $\left[\operatorname{Ir}(\mathrm{ppy})_{2}\right.$ acac] case for which TDDFT calculations performed at the $T_{1}$ geometry indicate that the acac-based lowest triplet state is very energetically separated from lowest excited state $(0.58 \mathrm{eV})$.

The proximity of the lowest cyclometallated- and acacbased excited states in N966 is opposed to well characterized ppy-based emission found in $\left[\operatorname{Ir}(\mathrm{ppy})_{2}\right.$ acac], suggesting the origin for the broad emission spectrum observed for N966. Vibronic coupling between bright and dark almost degenerate excited states is indeed considered to be a major source of spectral broadening in small to medium size molecules. ${ }^{11}$ The room-temperature emission spectra can be fitted with five gaussians, each separated by about $1300 \mathrm{~cm}^{-1}$, that is about one vibrational quantum of typical $\mathrm{C}-\mathrm{C}$ aromatic stretching vibration (Fig. S8, ESI $\dagger$ ). These are indeed the geometrical parameters which are mostly varied on going from $S_{0}$ to $T_{1}$ (Table S1, ESI $\dagger$ ) and correspondingly, the modes mainly involved in the vibrational sub-structure of emission spectra in related iridium complexes. ${ }^{12}$ We stress here that we have no evidence of dual-emission for N966, rather a single emitting 


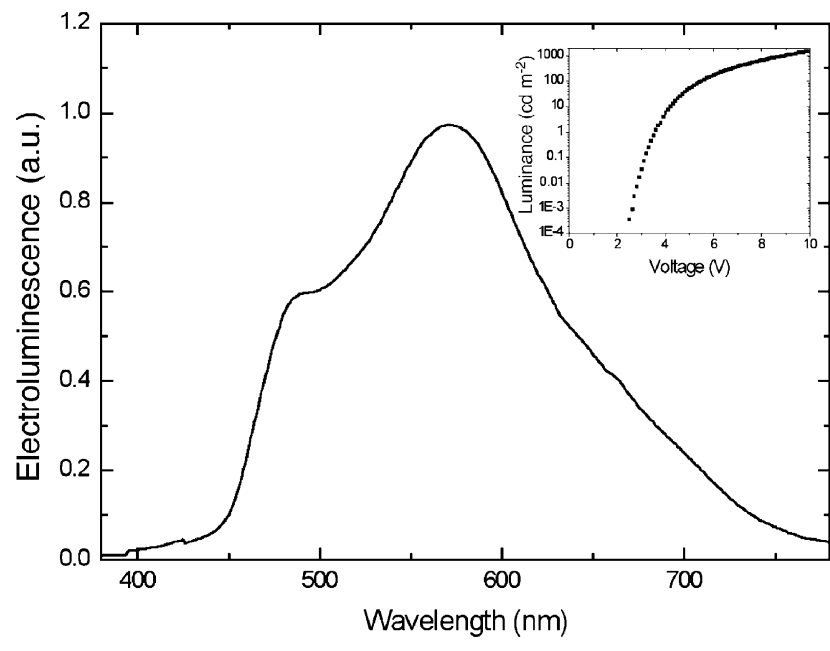

Fig. 3 Device: (ITO|PEDOT:PSS $\mid$ TCTA:N966|TPBI $|\mathrm{Ba}| \mathrm{Ag}$, ratio TCTA : N966 $=6: 4$ ). Inset shows the luminance $v s$. voltage.

excited state of mixed character seems to be the origin of the broad emission.

To verify the emission spectra of N966 under electronic excitation, a simple, partly solution processed, light emitting diode was fabricated, the emitting layer consisting only of N966 and a hole transporting molecule $4,4^{\prime}, 4^{\prime \prime}$-tri( $N$-carbazolyl)triphenylamine (TCTA) in a $4: 6$ ratio. Due to the presence of the methyl groups on the 2-phenylimidazole ligand, the N966 complex rapidly dissolves in a wide range of commonly used solvents (see ESI $\dagger$ ).

The electroluminescence spectrum of the N966-containing OLED, Fig. 3, is very broad with maxima around $570 \mathrm{~nm}$, having a FWHM of $165 \mathrm{~nm}\left(\mathrm{FWHM} \approx 5490 \mathrm{~cm}^{-1}\right.$; CIE: $x=$ $0.281 ; y=0.360)$. It should be noted that TCTA has its electroluminescence maximum around $410 \mathrm{~nm}^{13}$ and therefore does not contribute to the emission observed in the N966 device. The electroluminescence profile coincides with that observed from the solution emission spectra, indicating their similar origin and it rules out the formation of excimers as the source for the broad emission. The device reaches a luminance value of more than $1000 \mathrm{~cd} \mathrm{~m}^{-2}$ at a driving voltage of $9 \mathrm{~V}$ and an efficiency of $1 \mathrm{~cd} \mathrm{~A}^{-1}$. Efficient injection and transport of the two carriers is manifested by the low turn-on voltage (3.1 V). $I-V-L$ curves of the device are shown in Fig. S10 (ESI $\dagger$ ). PLQY of N966 in a PMMA matrix (5 wt\%) and in a thin film of the same composition as the emissive layer of the OLED have been measured by means of an integrated sphere, and are 0.07 and 0.05 , respectively. Hence the PLQY is increased by one order of magnitude in the solide state (photoand electroluminescence) compared to that in solution, in accordance with observations recently published for another phosphorescent complex. ${ }^{14}$

In summary, an iridium(III) complex is developed to have degenerate emitting states of mixed character, inducing a very broad emission perceived as white light upon photoexcitation and electro-excitation. Though the device efficiency is rather low, the preparation of a single component white light-emitting phosphorescent emitter is significant as it demonstrates the large potential that simple single organo-metallic complexes have for the development of white LEDs.

We acknowledge financial support for this work by The Solvay, Centrale Recherche et Technologie Division the European Union CombOLED-STRP-215934, ESF Eurocores05SONS-FP-021 and the Spanish Ministry of Science and Innovation. F. D. A. and S. F. thank MIUR-FIRB 2003 and CNR-PROMO 2006 for financial support. We thank Dr Rosario Scopelliti for X-ray analysis and Sonsoles Garcia for assistance in device preparation.

\section{Notes and references}

1 (a) D. Tanaka, H. Sasabe, Y.-J. Li, S.-J. Su, T. Takeda and J. Kido, Jpn. J. Appl. Phys., Part 2, 2007, 46, L10; (b) G. Gustafsson, Y. Cao, G. M. Treacy, F. Klavetter, N. Colaneri and A. J. Heeger, Nature, 1992, 357, 477; (c) V. Bulovic, G. Gu, P. E. Burrows, S. R. Forrest and M. E. Thompson, Nature, 1996, 380, 29.

2 (a) B. W. D'Andrade, M. E. Thompson and S. R. Forrest, $A d v$. Mater., 2002, 14, 147; (b) B.-P. Yan, C. C. C. Cheung, S. C. F. Kui, H. -F. Xiang, V. A. L. Roy, S.-J. Xu and C.-M. Che, Adv. Mater., 2007, 19, 3599.

3 B. W. D'Andrade, R. J. Holmes and S. R. Forrest, Adv. Mater., 2004, 16, 624.

4 Y. Sun, N. C. Giebink, H. Kanno, B. Ma, M. E. Thompson and S. R. Forrest, Nature, 2006, 440, 908.

5 (a) J. Luo, X. Li, Q. Hou, J. Peng, W. Wang and Y. Cao, Adv. Mater., 2007, 19, 1113; (b) J. Liu, Z. Xie, Y. Cheng, Y. Geng, L. Wang, X. Jing and F. Wang, Adv. Mater., 2007, 19, 531; (c) F.-I. Wu, X.-H. Yang, D. Neher, R. Dodda, Y.-H. Tseng and C.-F. Shu, Adv. Funct. Mater., 2007, 17, 1085.

6 P. Coppo, M. Duati, V. N. Kozhevnikov, J. W. Hofstraat and L. De Cola, Angew. Chem., Int. Ed., 2005, 44, 1806.

7 (a) E. L. Williams, K. Haavisto, J. Li and G. E. Jabbour, $A d v$. Mater., 2007, 19, 197; (b) X. Yang, Z. Wang, S. Madakuni and J. G. Jabbour, Adv. Mater., 2008, 20, 2405; (c) V. Adamovich, J. Brooks, A. Tamayo, A. M. Alexander, P. I. Djurovich, B. W. D'Andrade, C. Adachi, S. R. Forrest and M. E. Thompson, New J. Chem., 2002, 26, 1171.

8 The shape of the spectra is independent of the N966 batch, the purification step or method, and the presence or absence of oxygen in the solution. Therefore it is very unlikely originating from an impurity.

9 S. Lamansky, P. Djurovich, D. Murphy, F. Abdel-Razzaq, R. Kwong, I. Tsyba, M. Bortz, B. Mui, R. Bau and M. E. Thompson, Inorg. Chem., 2001, 40, 1704.

10 F. De Angelis, S. Fantacci, N. Evans, C. Klein, S. M. Zakeeruddin, J.-E. Moser, K. Kalyanasundaram, H. J. Bolink, M. Grätzel and M. K. Nazeeruddin, Inorg. Chem., 2007, 46, 5989.

11 (a) R. Brandi, F. Santoro and C. Petrongolo, Chem. Phys., 1997, 225, 55; (b) R. P. Krawczyk, K. Malsch, G. Hohlneicher, R. C. Gillen and W. Domcke, Chem. Phys. Lett., 2000, 320, 535.

12 F. De angelis, F. Santoro, M. K. Nazeeruddin and V. Barone, J. Phys. Chem. B, 2008, 112, 13181.

13 H. Etori, T. Yasuda, X. L. Jin, K. Fujita, S. Mataka and T. Tsutsui, Jpn. J. Appl. Phys., Part 1, 2007, 46, 5071.

14 E. Baranoff, S. Suàrez, P. Bugnon, H. J. Bolink, C. Klein, R. Scopelliti, L. Zuppiroli, M. Grätzel and M. K. Nazeeruddin, ChemSusChem, 2009, 2, 305. 